\title{
ФОРМИРОВАНИЕ СТРУКТУРЫ ЦЕМЕНТНОГО КАМНЯ НА ОСНОВЕ ВЯЖУЩИХ ЩЕЛОЧНОЙ АКТИВАЦИИ
}

\author{
Саламанова М.Ш., ${ }^{1,2}$ \\ Гацаев 3.Ш., \\ Муртазаева P. C-A. ${ }^{1}$ \\ ${ }^{1}$ Грозненский государственный нефтяной технический \\ университет имени академика \\ М.Д. Миллионщикова, г. Грозный, Россия \\ ${ }^{2}$ Комплексный научно-исследовательский институт \\ имени Х.И. Ибрагимова РАН, г. Грозный, Россия
}

Антропогенная нагрузка на природно-ресурсный потенциал планеты стремительно растет, поэтому особое внимание уделяется разработке менее затратных и мало энергоемких технологий получения новых строительных материалов, реализация которых не требует высокотемпературной и дорогой технологической обработки, и позволит использовать местные вторичные и некондичионные сырьевые материальы. В работе раскрываются вопросы, связанные с теоретическими основами формирования структуры и прочности цементного камня на основе щелочного активатора.

Ключевые слова: бесклинкерные вяжущие, термоактивированный мергель, щелочной активатор, метасиликат натрия, нормальная густота, минеральный порошок.

Механизм действия бесклинкерных вяжущих щелочной активации достаточно сложный и зависит от многих факторов, но научно-теоретические основы формирования шлакощелочных композиций, позволяют его рассматривать, как многокомпонентную систему, состоящую из дисперсных разновидностей алюмосиликата в аморфном и кристаллическом состоянии, затворенную раствором щелочных металлов, образующийся щелочной цементный камень представлен трехмерным каркасным алюмосиликатом из тетраэдров $\mathrm{SiO}_{4}$ и $\mathrm{AlO}_{4}$ с общими связями из щелочных катионов. Щелочные катионы компенсируют отрицательный заряд, возникающий при встраивании тетраэдров $\mathrm{AlO}_{4}$ между тетраэдрами $\mathrm{SiO}_{4}$. Алюминий в полимерном каркасе дает дефицит положительного заряда, который в свою очередь компенсируется щелочными катионами, прочно защемленными в структуре алюмосиликатного каркаса [1-5, 7]. Щелочной цементный камень состоит из таких соединений, как тоберморитоподобные низкоосновные гидросиликаты кальция $\mathrm{CSH}(\mathrm{B})$, гидрогранаты переменного состава, гель кремниевой кислоты, щелочные гидроалюмосиликаты типа природных цеолитов и гидрослюд и др. щелочнощелочноземельных соединений переменного состава $[7,8]$. 
Вопросы, связанные с теоретическими основами формирования структуры и прочности цементного камня на основе щелочного активатора, остаются недостаточно изученными и требуют глубокого исследования. А ожидаемые результаты исследований будут интересны специалистам строительной отрасли, так как предлагаемые рецептуры бесклинкерных цементов являются альтернативой дорогому и энергоемкому портландцементу и обеспечивают создание прочных и долговечных бетонных и железобетонных композитов [9-12].

Природно-ресурсный потенциал горной территории Северного Кавказа позволяет получать многокомпонентные вяжущие системы для получения долговечных строительных композитов (рис.1).

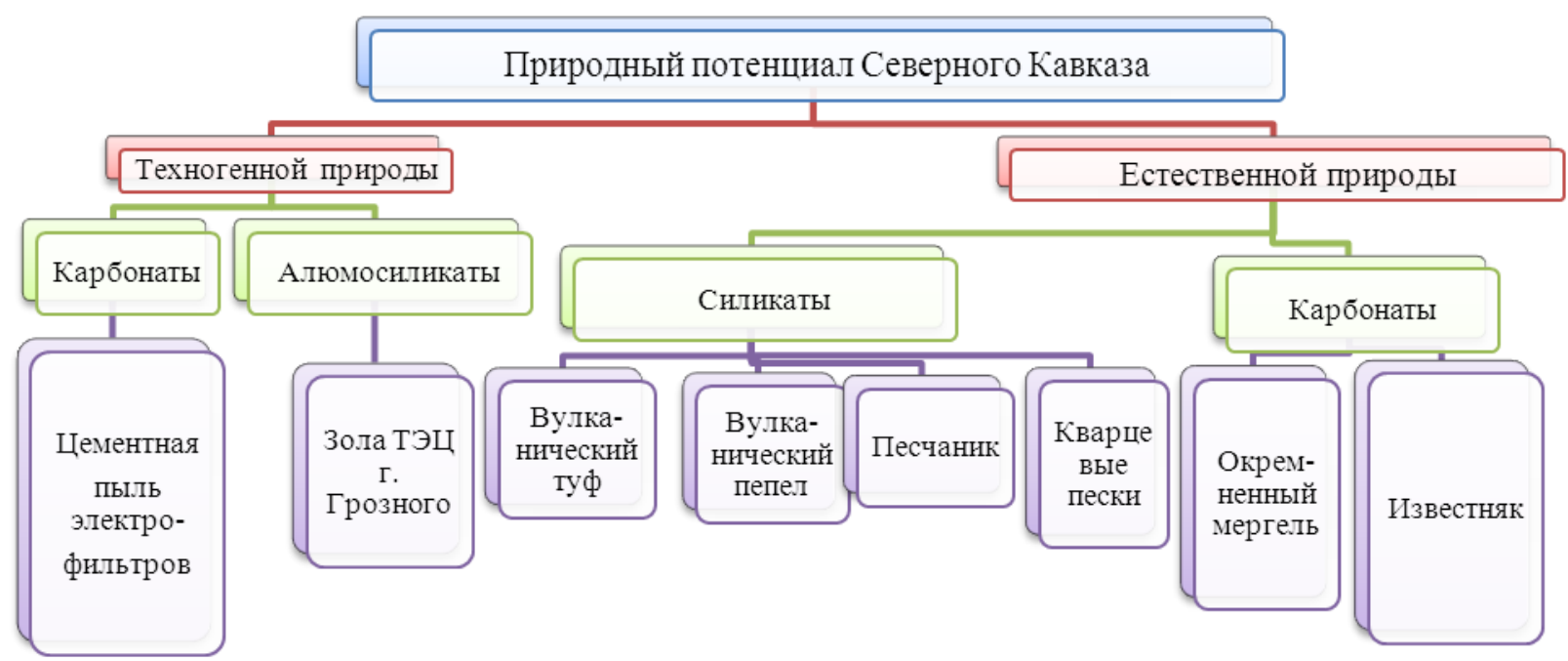

Рис. 1 - Природные и техногенные ресурсы Северного Кавказа

В качестве активной минеральной добавки для разработки оптимальных рецептур многокомпонентных бесклинкерных вяжущих связок, с использованием щелочного активатора, исследовалась горная порода осадочного происхождения - окремненный мергель (опока), которая состоит из опала с примесями глинистых минералов, минеральных зерен и скелетов микроорганизмов.

В Чеченской Республике достаточно много месторождений окремненного мергеля с достаточно большим объемом сырья (рис.2). Для более полного проявления гидравлических свойств методикой проведения экспериментов предполагалось, что исследуемая порода подвергалась различным технологическим воздействиям, в частности, крупному измельчению в щековой дробилке и тонкому - в вибрационной шаровой мельнице в течении 20 минут. На следующем этапе полученный тонкодисперсный порошок с удельной поверхностью $580 \mathrm{~m}^{2} /$ кг в течение 2,5 часов помещался в муфельную печь для теплового воздействия при температуре $700{ }^{\circ} \mathrm{C}$. 

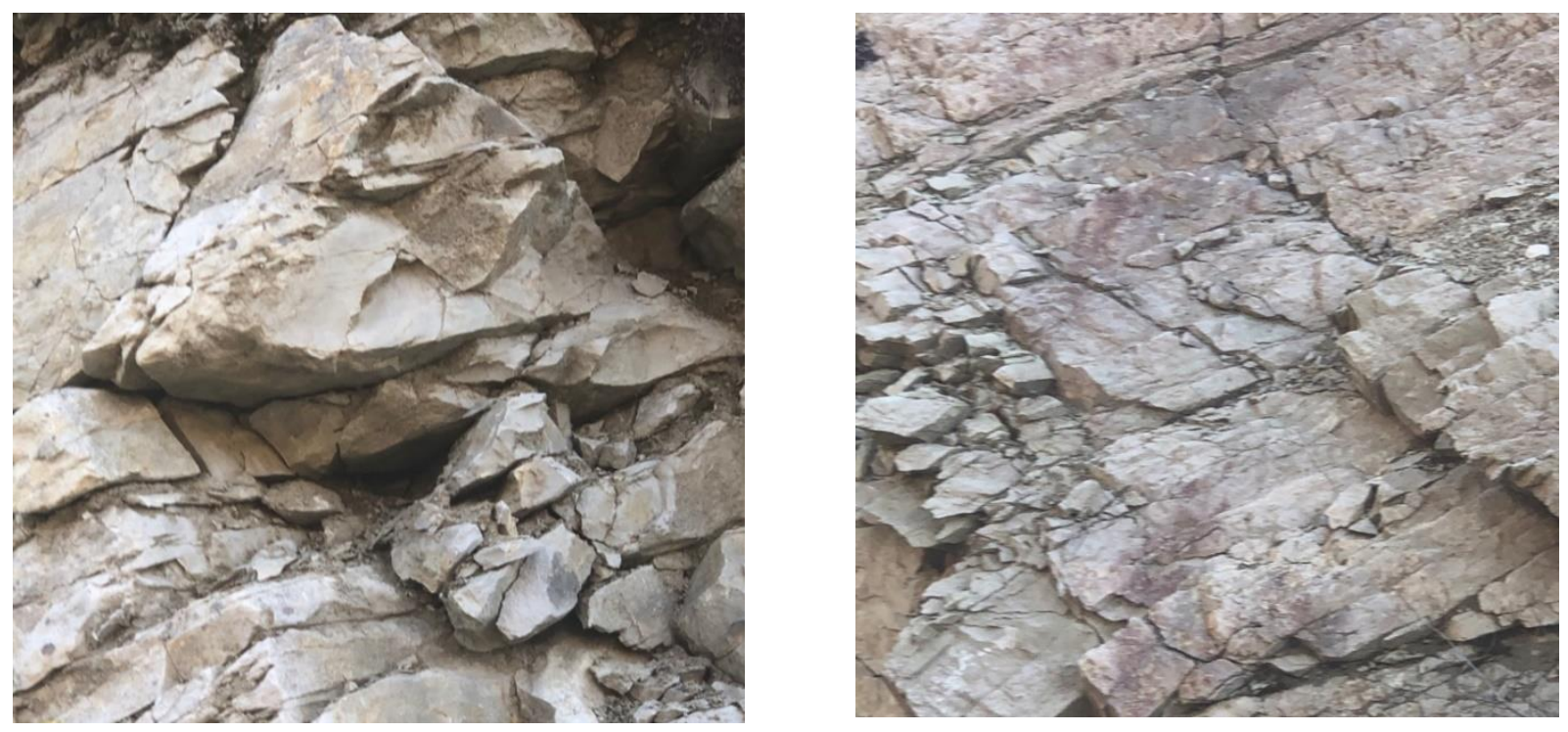

Рис. 2 - Фрагмент многочисленных пород окремненного мергеля на территории Чеченской Республики

После подобной термоактивации с целью повышения активности часть порошка домалывали в мельнице до достижения им оптимальной степени дисперсности. Внешне полученный тонкодисперсный порошок из мергеля после помола имеет серый цвет, а порошок из термообработанного мергеля имеет светло коричневый цвет.

Электронно-зондовые исследования на растровом электронном микроскопе VEGA II LMU показали следующий оксидный состав \% по массе:

- окремненного мергеля: $\mathrm{MgO}=1,10 ; \mathrm{Al}_{2} \mathrm{O}_{3}=5,47 ; \mathrm{SiO}_{2}=28,7 ; \mathrm{Na}_{2} \mathrm{O}=$ 1,$09 ; \mathrm{CaO}=61,53 ; \mathrm{Fe}_{2} \mathrm{O}_{3}=2,12$;

- окремненного мергеля термообработанного при температуре $700{ }^{0} \mathrm{C}$ : $\mathrm{CO}_{2}=31,49 ; \mathrm{MgO}=0,41 ; \mathrm{Al}_{2} \mathrm{O}_{3}=2,20 ; \mathrm{SiO}_{2}=28,53 ; \mathrm{Na}_{2} \mathrm{O}=0,58 ; \mathrm{CaO}=35,92 ;$ $\mathrm{Fe}_{2} \mathrm{O}_{3}=0,86$.

Изучение частиц окремнённого мергеля до и после термоактивация при температуре $700{ }^{\circ} \mathrm{C}$ методом сканирующей электронной микроскопии и рентгенофазового анализа спектры фаз основной массы окремненного мергеля в естественном виде выявили присутствие в преобладании таких минералов, как кальцит, алюмосиликаты, представленные полевыми шпатами, кварцем и каолинитом (рис. 3, таблица 1).
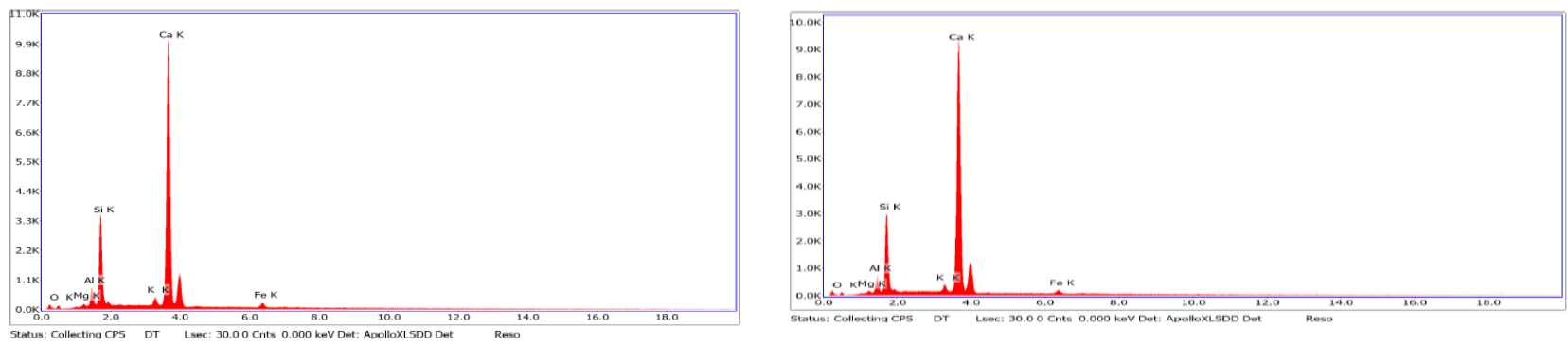

Рис. 3 - Спектры EDX фаз основной массы 
Таблица 1. Состав в вес. \%

\begin{tabular}{|c|c|c|c|c|c|c|}
\hline Спектр & $\mathrm{Na}_{2} \mathrm{O}$ & $\mathrm{MgO}$ & $\mathrm{Al}_{2} \mathrm{O}_{3}$ & $\mathrm{SiO}_{2}$ & $\mathrm{CaO}$ & $\mathrm{FeO}$ \\
\hline 1 & 1.02 & 0.66 & 5.01 & 27.13 & 64.02 & 2.16 \\
\hline 2 & 0.64 & 0.97 & 2.92 & 26.83 & 67.84 & 0.80 \\
\hline
\end{tabular}

Спектры фаз основных масс окремненного мергеля после термоактивации $700{ }^{0} \mathrm{C}$ выявили присутствие ларнита $\mathrm{Ca}_{2} \mathrm{SiO}_{4}$ (рис. 4, таблица 2).
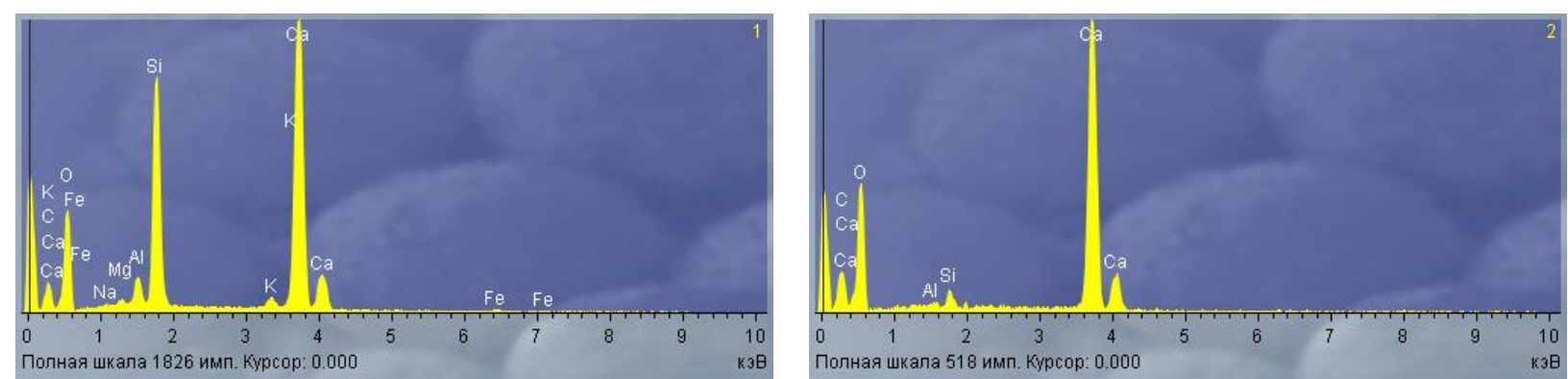

Рис. 4 - Спектры EDX фаз основной массы

Таблица 2. Состав в вес. \%

\begin{tabular}{|c|c|c|c|c|c|c|c|}
\hline Спектр & $\mathrm{Na}_{2} \mathrm{O}$ & $\mathrm{MgO}$ & $\mathrm{Al}_{2} \mathrm{O}_{3}$ & $\mathrm{SiO}_{2}$ & $\mathrm{CaO}$ & $\mathrm{FeO}$ & ппп \\
\hline 1 & 0.06 & 0.25 & 3.17 & 30.11 & 61.27 & 0.24 & 4,90 \\
\hline 2 & 0.00 & 0.00 & 0.32 & 4.64 & 69.63 & 0.00 & 25.41 \\
\hline
\end{tabular}

По результатам рентгенофазового анализа в образцах порошка термоактивированного мергеля присутствуют яркие фазы кальцита и менее яркие кварца, в очень небольшом количестве полевые шпаты, вероятнее всего плагиоклазы, на 9 град. пик, примерно соответствует слюдам-гидрослюдам (рис. 5).

Наблюдается несколько «размытых» рефлексов, сходных с рефлексами силикатов кальция (типа ларнита) и окисью кальция, яркий пик накладывается с одной из линий предположенного ларнита, вторая не яркая совпадает с галоподобным участком, возможно, связанным с присутствием слабо окристаллизованных силикатов кальция, так же в районе 18 град. есть небольшое гало, которое можно идентифицировать к фазе портландита.

Рентгенофазовый качественный анализ установил присутствие силикатов и алюмосиликатов кальция различной основности, поэтому на следующем этапе была поставлена цель установить эффективность выбранного технологического приема, так как тепловая обработка влечет за собой определенные затраты на энергоресурс и оборудование. 


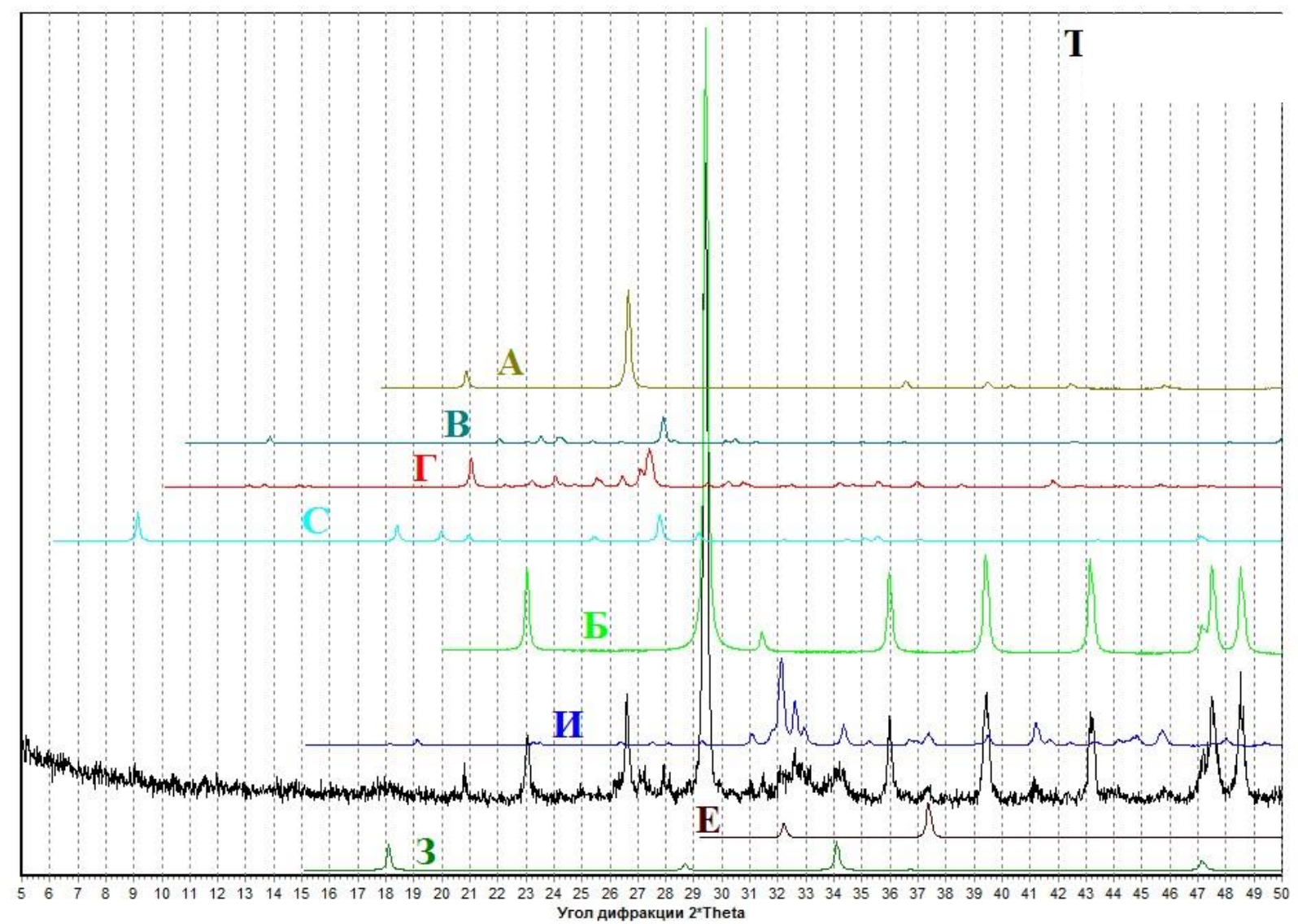

Ри

с. 5 - Дифрактограмма образца термоактивированного мергеля $700{ }^{0} \mathrm{C}$, в сопоставлении с данными базы PDF-2. Приведенные фазы сравнения: А кварц, Б - кальцит, В - альбит, С - парагонит, 3 -портландит, Е - оксид кальция, И - ларнит, Г - микроклин/ортоклаз

Для решения поставленной задачи подготовленные порошки из окремненного мергеля подвергнутые как тонкому измельчению, так и термообработке затворяли водой и щелочным раствором. В качестве щелочного затворителя использовали жидкое натриевое стекло с силикатным модулем 2,8 и плотностью 1,24 г/см³ мергелем без термообработки применяли кремнефтористый натрий $\mathrm{Na}_{2} \mathrm{SiF}_{6} \mathrm{c}$ дозировкой 6\% от массы жидкого стекла. Удельная поверхность минеральных порошков, подготовленных для активации составила $S_{\text {уд }}=580-590 \mathrm{~m}^{2} / \kappa г$.

Структуру цементного камня щелочной активации можно представить гетерофазной дисперсной системой, в которой активными составляющими являются практически все компоненты, процесс структурообразования исследуемой системы можно представить следующими структурными элементами:

- дисперсионная среда;

- межфазовая диффузионная контактная зона «частицы порошка - гель $\mathrm{Na}_{2} \mathrm{SiO}_{3} \gg$

- реакционный минеральный порошок, состоящий из прореагировавшей и непрореагировавшей составляющих. 
В результате затворения смеси минерального порошка и заполнителя щелочным раствором, происходит повышение энергетического потенциала на поверхности частиц минерального порошка, пространство между зернами твердой фазы уменьшается, жидкая фаза перераспределяется к зоне контакта «частицы порошка - гель $\mathrm{Na}_{2} \mathrm{SiO}_{3}$ », поверхность минеральных частиц является подложкой для кристаллизации новообразований.

В подтверждение выдвинутых гипотез формирования структуры проводились электронно-зондовые исследования на растровом электронном микроскопе VEGA II LMU. Рентгенофазовый качественный анализ выполнялся на отражение по Бреггу-Брентано на дифрактометре «ARLX'TRA», использующем кинематическую схему $\Theta-\Theta$ с горизонтальным расположением плоского образца.

Исследуемые образцы цементного камня щелочного затворения из термоактивированного мергеля при $700{ }^{0} \mathrm{C}$ характеризуются тем, что микроструктура основной массы образована не окристаллизованными агрегатами гидроалюмосиликатного «цеолитового» состава с переменным отношением $\mathrm{Ca} / \mathrm{Na}$ (рис. 6, табл. 3, анализы $1,2,5,6$ ), кальцитом (табл. 3, анализы 3, 5, 6), фазами, близкими по составу к двухкальциевым гидросиликатам (табл. 4, анализ 4) и, возможно, гидроксидом кальция. Железо и магний связаны с алюмосиликатными гидратными соединениями.

Таблица 3. Результаты анализа типичных микрофаз (участки анализа на рис. 6)

\begin{tabular}{|c|c|c|c|c|c|c|c|}
\hline Спектр & $\mathrm{Na}_{2} \mathrm{O}$ & $\mathrm{MgO}$ & $\mathrm{Al}_{2} \mathrm{O}_{3}$ & $\mathrm{SiO}_{2}$ & $\mathrm{~K}_{2} \mathrm{O}$ & $\mathrm{CaO}$ & ппП \\
\hline 1 & 11.46 & 0.00 & 19.49 & 54.26 & 0.00 & 2.34 & 12.46 \\
\hline 2 & 6.29 & 0.00 & 15.72 & 57.93 & 0.00 & 9.01 & 11.05 \\
\hline 3 & 1.14 & 0.23 & 0.29 & 2.19 & 0.00 & 41.97 & 54.19 \\
\hline 4 & 2.23 & 0.52 & 0.91 & 16.70 & 0.18 & 39.59 & 39.87 \\
\hline 5 & 0.85 & 0.55 & 0.56 & 6.69 & 0.00 & 42.13 & 49.22 \\
\hline 6 & 0.82 & 0.00 & 0.56 & 4.97 & 0.00 & 39.96 & 53.69 \\
\hline
\end{tabular}

Электронно-зондовые исследования цементного щелочного камня показали, что в исследуемой системе присутствует гидроалюмосиликатная цеолитовая фаза переменного состава, позволяющая получать прочные и долговечные искусственные строительные композиты, конкурирующие с бетонами на портландцементе.

Таким образом, предлагаемая бесклинкерная технология вяжущих связок щелочной активации с использованием термоактивированного при температуре 700 0С мергеля наиболее целесообразна и актуальна, особенно в регионах с отсутствием отходов черной металлургии, технология которых изучена и широко применяется по всему миру. 


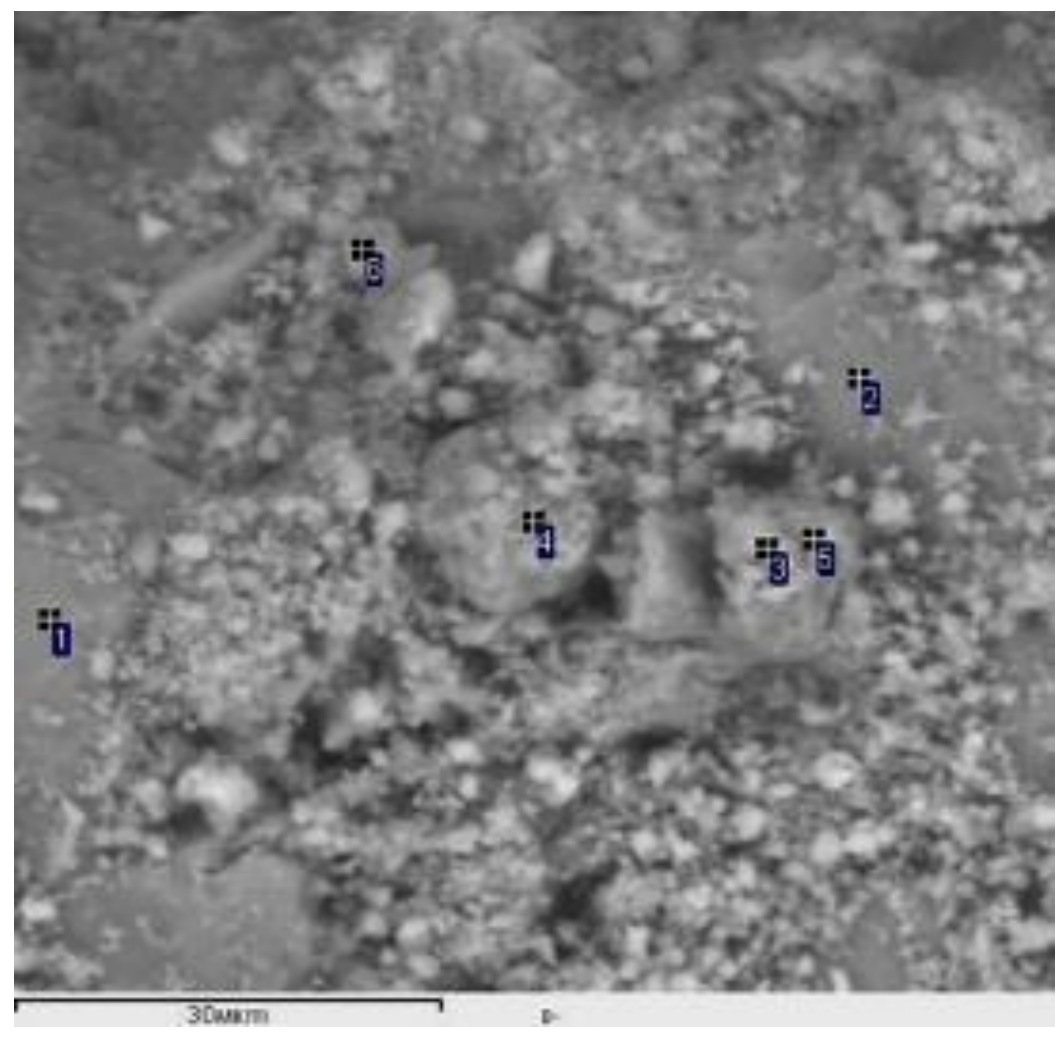

Рис. 6 - Типичное микростроение основной массы

Применительно к регионам Северного Кавказа необходимо учитывать огромные транспортные затраты на перевозку доменных гранулированных шлаков и дополнительные расходы на механоактивацию в дорогом помольном оборудовании. Поэтому предлагаемая технология позволит создавать новые строительные материалы с меньшими энерго- и ресурсозатратами и одновременно окажет весомый вклад в улучшение экологической обстановки, окружающей нас среды.

Исследование выполнено при финансовой поддержке РФФИ в рамках научного проекта № 18-48-200001.

\section{Список литературы}

1. Кочетов, В.А. Римский бетон [Текст] / В.А. Кочетов //- М: Стройиздат, 1991. $-128 \mathrm{c}$.

2. Соломатов, В.И., Тахаров М.К., Тахер Шах Мд. Интенсивная технология бетонов [Текст] / В.И. Соломатов, М.К. Тахаров, Шах Мд.Тахер // М. Стройиздат, 1989. - 264 с.

3. Муртазаев, С-А.Ю. Влияние активных центров поверхности на реакционную способность минеральных добавок [Текст] / С-А.Ю. Муртазаев, М.Ш. Саламанова, М.С. Сайдумов, З.Х. Исмаилова // Научный журнал «Современная наука и инновации» (Ставрополь - Пятигорск). - 2017. - №2 (18). - C.168-175. 
4. Муртазаев,

C-A.Ю.

Перспективы

использования термоактивированного сырья алюмосиликатной природы [Текст] / С-А.Ю. Муртазаев, М.Ш. Саламанова// Приволжский научный журнал. - 2018. - №2 (T.46). - C. $65-70$.

5. Murtazayev S- A. Yu., Salamanova M.Sh., Alashanov A., Ismailova Z. Features of Production of Fine Concretes Based on Clinkerless Binders of Alkaline Mixing (Особенности получения мелкозернистых бетонов на основе бесклинкерных вяжущих щелочного затворения) 14th International Congress for Applied Mineralogy (ICAM 2019) Belgorod State Technological University named after V. G. Shukhov, 23-27 September 2019, Belgorod: 2019. - pp.385-388.

6. Маянц, М.М. Использование зол и шлаков ГЭС в промышленности строительных материалов [Текст] / М.М. Маянц // Обзор. - М:,1970. - 123с.

7. Рахимова, Н.Р. Состояние и перспективные направления развития исследований и производства композиционных шлакощелочных вяжущих, растворов и бетонов [Текст] / Н.Р. Рахимова // Строительные материалы. 2008. - №9. - C.77-80.

8. Hardjito, D. On the development of fly ash-based geopolymer concrete / D. Hardjito, S. Wallah, D. Sumajouw, B. Rangan // ACJ Materials Journal. - 2004. vol.101. №6. - pp.467-472.

9. Кривенко, П.В. Эксплуатационные свойства бетона на шлакощелочном цементе [Текст] / П.В. Кривенко // Строительные материалы и конструкции; -Киев, 1980. - № 4. - С.23.

10. Garcia-Luna, A. Microsilextm a new material to improve environmental performance of cement and concrete / A. Garcia-Luna, H. Minard, C. Prieto-Gomez, C. Soare, M. Viviani // Proceed. 3rd International Symposium "Non-traditional cement\&concrete" (Bmo). - pp. 237-244.

11. Murtazayev S- A. Yu., Salamanova M.Sh., Mintsaev M.Sh., Bisultanov R.G Fine-Grained Concretes with Clinker-Free Binders on an Alkali Gauging (Мелкозернистые бетоны на основе вяжущих щелочной активации) Proceedings of the International Symposium "Engineering and Earth Sciences: Applied and Fundamental Research" dedicated to the 85th anniversary of H.I. Ibragimov (ISEES 2019). Atlantis Highlights in Material Sciences and Technology (AHMST). April 2019. Vol.1. - P.500-503.

12. Bataev D.K-S., S- A. Yu. Murtazayev, Salamanova M.Sh., Viskhanov S.S. Utilization of Cement Kiln Dust in Production of Alkali-Activated Clinker-Free Binders (Использование цементной пыли в производстве бесклинкерных вяжущих щелочной активации) / Proceedings of the International Symposium "Engineering and Earth Sciences: Applied and Fundamental Research" dedicated to the 85th anniversary of H.I. Ibragimov (ISEES 2019). Atlantis Highlights in Material Sciences and Technology (AHMST). April 2019. Vol.1. - P.457-460. 